\title{
Petroclival meningiomas: is radical resection always the best option?
}

\author{
Josef Zentner, Bernhard Meyer, Uwe Vieweg, Claus Herberhold, Johannes Schramm
}

\begin{abstract}
Background-The surgical management of petroclival meningiomas is, despite the invaluable technical achievements in the past decade, still burdened by a high operative morbidity. It seems doubtful whether radical surgical removal should always be the primary goal in those lesions as advocated until very recently. Methods-A series was critically analysed and the literature discussed to elucidate criteria for a different attitude. Between 1990 and 1995 a total of 19 patients harbouring petroclival meningiomas were operated on. The following approaches were used: petrosal $(n=13)$, retrosigmoidal $(n=5)$, and subtemporal $(n=1)$. Thirteen lesions were removed completely and six incompletely as assessed by postoperative MRI.

Results-No recurrence or regrowth could be detected on MRI after a mean follow up of 18 months. Surgical mortality occurred in one patient (5\%) and there was early postoperative dysfunction in $56 \%$. At the time of follow up major permanent operative morbidity was present in two patients $(11 \%)$.

Conclusions-In accord with recent literature subtotal resection of petroclival meningiomas should be contemplated in a subset of patients (with invasion of brain stem or cavernous sinus) to reduce the incidence of disabling deficits. Surgery should not be delayed in younger patients because surgical morbidity relates positively with tumour size.
\end{abstract}

$(\mathcal{F}$ Neurol Neurosurg Psychiatry 1997;62:341-345)

Department of Neurosurgery

J Zentner

B Meyer

U Vieweg

J Schramm

Department of

Otolaryngology,

University of Bonn,

Germany

C Herberhold

Correspondence to:

Professor Josef Zentner,

Department of

Neurosurgery, University of

Bonn, Sigmund Freud

Strasse 25, 53127 Bonn

Germany.

Received 2 February 1996 and in revised form

Accepted 3 December 1996 particularly meningiomas, have undergone a remarkable and probably predictable evolution. Because the operative mortality for petroclival meningiomas has been reported to be as high as $56 \%$ before 1980 , their removal was regarded as a "formidable challenge". However, the inherent fascination of technical challenges and the potential to cure meningiomas triggered the predictable part of the development.

With the simultaneous expansion of microneurosurgery, specialised skull base centres introduced new complex approaches and surgical techniques based on extensive anatomical studies. Subsequently reported surgical series-from the mid-1980s on-had a much lower mortality rate, ranging from 0 to 9\%. ${ }^{1-19}$ However, temporary and permanent operative morbidity in all those reports still tended to be high. An immediate postoperative worsening was seen in virtually all patients. Permanent morbidity reached up to $50 \%$, with severe disabilities in up to $18 \%$. Although all authors openly reported those complication rates, the rather trite conclusion remained the same for the past 10 years: Radical tumour removal should be the primary goal in all cases, because it can be achieved by new and elegant techniques. The morbidity and mortality were simply considered acceptable by almost all authors. Only rarely were doubts expressed about this point of view. ${ }^{14} 20$

Recently, some of those that had spearheaded many innovations and surgical aggressiveness in skull base surgery advocated a much more differentiated and critical attitude. ${ }^{21-23} \mathrm{We}$ are encouraged to report our own series of petroclival meningiomas and review the current literature as we have simultaneously reached similar conclusions.

\section{Patients and methods}

Between 1990 and 199519 patients were operated on for petroclival meningiomas. Two men and 17 women with a mean age of 56 (range 31-75) years, underwent a total of 20 procedures. Preoperative symptoms were mostly mild and thus Karnofsky performance scores (KPS) were high with a median of 80 (range 70-90). Six patients exhibited no symptoms or minor headaches only, whereas in nine cases intermediate symptoms such as cranial nerve deficits or limb and gait ataxia were present. Four patients had already developed motor weakness and hemisensory loss (table).

All patients underwent preoperative MRI

Published surgical series of petroclival lesions,

for evaluation of tumour size and exact anatomical correlation. Tumour size and location were classified according to Sekhar et al. ${ }^{17}$ Seven patients with suspected involvement of the internal carotid artery underwent additional preoperative angiography with balloon occlusion testing as a precaution in the case of arterial injury. In six patients simple standard approaches and in 13 patients so called complex skull base approaches were used (table). The technical details of the mentioned routes of access to the base of the skull are described in detail elsewhere. ${ }^{1-3} 581113$ 17-19 24-33 
Clinical data of 19 patients with petroclival meningiomas

\begin{tabular}{|c|c|c|c|c|c|c|c|c|c|c|c|c|}
\hline $\begin{array}{l}\text { Patient } \\
\text { No }\end{array}$ & Age & $\operatorname{Sex}$ & Location & Size & Approach & Resection & $\begin{array}{l}\text { Early } \\
\text { dysfunction }\end{array}$ & Morbidity & $\begin{array}{l}\text { Regrowth/ } \\
\text { recurrence }\end{array}$ & $F / U$ & $\begin{array}{l}\text { KPS } \\
\text { pre-op }\end{array}$ & $\begin{array}{l}K P S \\
F / U\end{array}$ \\
\hline 1 & 54 & $\mathbf{F}$ & $\mathrm{U} / \mathrm{M} / \mathrm{L}$ & Giant & Postpetrosal L* & Subtotal & $\begin{array}{l}\text { Haemorrhage, } \\
\text { CSF leak, } \\
\text { Infection, CN IV }\end{array}$ & No & No & 45 & 90 & 90 \\
\hline 2 & 74 & $\mathbf{F}$ & $M / L$ & Large & Subocc L & Total & No & No & No & 34 & 80 & 90 \\
\hline 3 & 47 & $\mathbf{M}$ & $\mathbf{U} / \mathbf{M}$ & Large & Post petrosal $\mathbf{R}$ & Total & No & No & No & 32 & 90 & 100 \\
\hline 4 & 56 & $\mathbf{M}$ & $\mathbf{M} / \mathbf{L}$ & Large & Subocc L & Total & CN VI, VII, VIII & CN VII, VIII & No & 28 & 90 & 90 \\
\hline 5 & 37 & $\mathbf{F}$ & $\mathrm{U} / \mathrm{M} / \mathrm{L}$ & Giant & Post petrosal L & Total & $\begin{array}{l}\text { CSF leak, CN } \\
\text { VII, VIII, altered } \\
\text { Mental status }\end{array}$ & CN VII, VIII & No & 26 & 90 & 80 \\
\hline $\begin{array}{l}6 \\
7\end{array}$ & $\begin{array}{l}66 \\
61\end{array}$ & $\begin{array}{l}\mathbf{F} \\
\mathbf{F}\end{array}$ & $\begin{array}{l}\mathrm{M} / \mathrm{L} \\
\mathrm{U} / \mathrm{M}\end{array}$ & $\begin{array}{l}\text { Large } \\
\text { Large }\end{array}$ & $\begin{array}{l}\text { Subocc L } \\
\text { Post petrosal L }\end{array}$ & $\begin{array}{l}\text { Total } \\
\text { Total }\end{array}$ & $\begin{array}{l}\text { No } \\
\text { CN VI }\end{array}$ & $\begin{array}{l}\text { No } \\
\text { Incomplete CN VI }\end{array}$ & $\begin{array}{l}\text { No } \\
\text { No }\end{array}$ & $\begin{array}{l}23 \\
22\end{array}$ & $\begin{array}{l}90 \\
80\end{array}$ & $\begin{array}{l}90 \\
90\end{array}$ \\
\hline 8 & 52 & $\mathbf{F}$ & $\mathrm{M} / \mathrm{L}$ & Large & Subocc R & Total & $\begin{array}{l}\text { CSF leak, } \\
\text { Infection }\end{array}$ & No & No & 18 & 80 & 90 \\
\hline 9 & 48 & $\mathbf{F}$ & $\mathbf{U} / \mathbf{M}$ & Medium & Post petrosal L & Total & No & No & No & 12 & 90 & 100 \\
\hline 10 & 42 & $\mathbf{F}$ & $\mathbf{U} / \mathbf{M}$ & Large & Post petrosal L & Subtotal & $\begin{array}{l}\text { Hemiparesis, altered } \\
\text { mental status }\end{array}$ & Hemiparesis & No & 26 & 80 & 90 \\
\hline 11 & 67 & $\mathbf{F}$ & $\mathbf{M}$ & Medium & Post petrosal L & Total & No & No & No & 10 & 90 & 100 \\
\hline 12 & 71 & $\mathbf{F}$ & $\mathrm{U} / \mathrm{M}$ & Large & Post petrosal $\mathrm{L}$ & Total & $\begin{array}{l}\text { Epidural haemat, } \\
\text { CN VI }\end{array}$ & $\begin{array}{l}\text { Incomplete CN } \\
\text { VI }\end{array}$ & No & 10 & 90 & 80 \\
\hline 13 & 75 & $\mathbf{F}$ & $\mathbf{U} / \mathbf{M}$ & Large & Post petrosal L & Subtotal & No & No & No & 10 & 70 & 70 \\
\hline 14 & 44 & $\mathbf{F}$ & $\mathrm{U}$ & Medium & Ant petrosal L & Total & $\begin{array}{l}\text { CSF leak, altered } \\
\text { mental status }\end{array}$ & No & No & 10 & 70 & 70 \\
\hline $\begin{array}{l}15 \\
16\end{array}$ & $\begin{array}{l}35 \\
74\end{array}$ & $\mathbf{F}$ & $\begin{array}{l}\mathrm{U} / \mathrm{M} / \mathrm{L} \\
\mathrm{U}\end{array}$ & $\begin{array}{l}\text { Giant } \\
\text { Medium }\end{array}$ & $\begin{array}{l}\text { Complpetrosal R } \\
\text { Subtemp L }\end{array}$ & $\begin{array}{l}\text { Subtotal } \\
\text { Subtotal }\end{array}$ & No & $\begin{array}{l}\text { No } \\
\text { No }\end{array}$ & $\begin{array}{l}\text { No } \\
\text { No }\end{array}$ & $\begin{array}{l}9 \\
9\end{array}$ & $\begin{array}{l}80 \\
80\end{array}$ & $\begin{array}{l}80 \\
80\end{array}$ \\
\hline $\begin{array}{l}17 \\
18 \\
19\end{array}$ & $\begin{array}{l}60 \\
31 \\
67\end{array}$ & $\begin{array}{l}\mathbf{F} \\
\mathbf{F} \\
\mathbf{F}\end{array}$ & $\begin{array}{l}\mathrm{L} \\
\mathrm{U} / \mathrm{M} / \mathrm{L} \\
\mathrm{U} / \mathrm{M} / \mathrm{L}\end{array}$ & $\begin{array}{l}\text { Medium } \\
\text { Giant } \\
\text { Giant }\end{array}$ & $\begin{array}{l}\text { Subocc L } \\
\text { Post petrosal R } \\
\text { Post petrosal L }\end{array}$ & $\begin{array}{l}\text { Total } \\
\text { Subtotal } \\
\text { Total }\end{array}$ & $\begin{array}{l}\text { No } \\
\text { CN III, V } \\
\text { Death (brainstem } \\
\text { infarct) }\end{array}$ & $\begin{array}{l}\text { No } \\
\text { No }\end{array}$ & $\begin{array}{l}\text { No } \\
\text { No }\end{array}$ & $\begin{array}{l}9 \\
9\end{array}$ & $\begin{array}{l}70 \\
80 \\
80\end{array}$ & $\begin{array}{l}90 \\
90 \\
\text { Patient } \\
\text { died }\end{array}$ \\
\hline
\end{tabular}

Location relates to involvement of clivus; $U=$ upper clivus (above CNV); $M=$ middle clivus (between CN V and CN IX); $L=$ lower clivus (below CN IX). Size is graded according to Sekhar et al ${ }^{17} ;$ medium $=1-2.5 \mathrm{~cm}$; large $=2.5-4.5 \mathrm{~cm} ;$ giant $=>4.5 \mathrm{~cm}$. Approaches are subocc $=$ simple suboccipital retrosigmoidal; subtem $p=$ simple subtemporal; ant petrosal = subtemporal with partial anterior petrosectomy; post petrosal = combined infra and supratentorial with partial posterior petrosectomy (= anterosigmoidal retrolabyrinthine); compl petrosal = combined infra/supratentorial with complete petrosectomy (= anterosigmoidal transcochlear) Resection is as determined by early ( $<3$ months after surgery) MRI. Early dysfunction defines the temporary operative morbidity including direct operative complications. Morbidity is the permanent operative morbidity at time of follow up. Regrowth/recurrence was determined by MRI at time of follow up. F/U = time of las follow up in months after surgery. KPS preop = Karnofsky performance score preoperatively. KPS F/U = Karnofsky performance score at time of last follow up.

Extent of tumour removal and recurrence or regrowth were evaluated by serial MRI. Clinical evaluations were performed during the first days after surgery and at regular follow up to establish (a) temporary operative morbidity and mortality and $(b)$ permanent operative morbidity. Mean follow up time was 18 (range 9-45) months.

\section{Results}

The table gives tumour size and location, and approaches used. All tumours were histopathologically classified as typical meningiomas (World Health Organisation (WHO) grade I). Complete tumour removal was achieved in 13 patients (68\%) as defined by postoperative MRI criteria. In the remaining six patients $(32 \%)$ remnants were intentionally left either inside the cavernous sinus $(n=3)$, or as small rims attached to the brain stem $(n=$ $1)$, or both ( $n=2)$ (fig 1). Brain stem oedema on preoperative MRI was considered indicative of adhesion or invasion by the tumour and therefore precluded total removal.

Recurrence within the limited time of follow up could not be shown in any of the patients with completely resected tumours. In those patients with tumour remnants in the cavernous sinus or at the brainstem surface, no progression could be detected after a short follow up of around 10 months in five patients and a period of 45 months in one patient.

The table lists all complications related to surgery. One patient died on the fifth postoperative day, accounting for the surgical mortality of $5 \%$. She developed a fulminant sepsis secondary to pneumonia while being ventilated on the intensive care unit for a severely depressed neurological status secondary to brain stem infarction. A radical removal of her giant petroclival meningioma had been attempted despite adherence to the brain stem. In the remaining patients direct operative complications in the immediate postoperative period were seen in six instances (34\%). One epidural haematoma and one intracerebral haemorrhage required reoperation with a further uneventful course in both cases. Of five patients with CSF leaks (28\%), four could be treated conservatively and one required definite surgical repair. Two patients developed postoperative meningitis (11\%) which resolved after antibiotic treatment without sequelae.

A substantial part of early postsurgical dysfunction was caused by psycho-organic disturbances with concomitant slow recovery, related to prolonged left temporal lobe retraction in four patients $(22 \%)$. Cranial neuropathies (six patients; $34 \%$ ) were the most frequent focal deficits causing early deterioration. Cranial nerves III through VI were mainly involved and in two patients the nerve group VII/VIII was also impaired. One other patient exhibited a hemiparesis after surgery.

Only eight patients (44\%) were not appreciably affected by one of the above complications in the early postoperative period. In these patients the postsurgical KPS dropped by only 20 points or less, whereas in the remaining 10 patients a drop of 30 or more occurred (table). Mean time resident in hospital in the neurosurgical department also differed significantly between these two groups (two weeks $v$ five weeks). All patients in the five week group were referred to a rehabilitation unit and spent up to seven months there.

At the time of the last follow up five patients still exhibited deficits and thus accounted for 
Gadolinium enhanced $T 1$ weighted MRI before $(A)$ and after (B) subtotal resection of a giant right sided petroclival

meningioma in a 31 year old woman. The

postoperative course was uneventful except for a transient CN III and V paresis. Note tumour remnants that were left intentionally inside the cavernous sinus and around the brain stem.
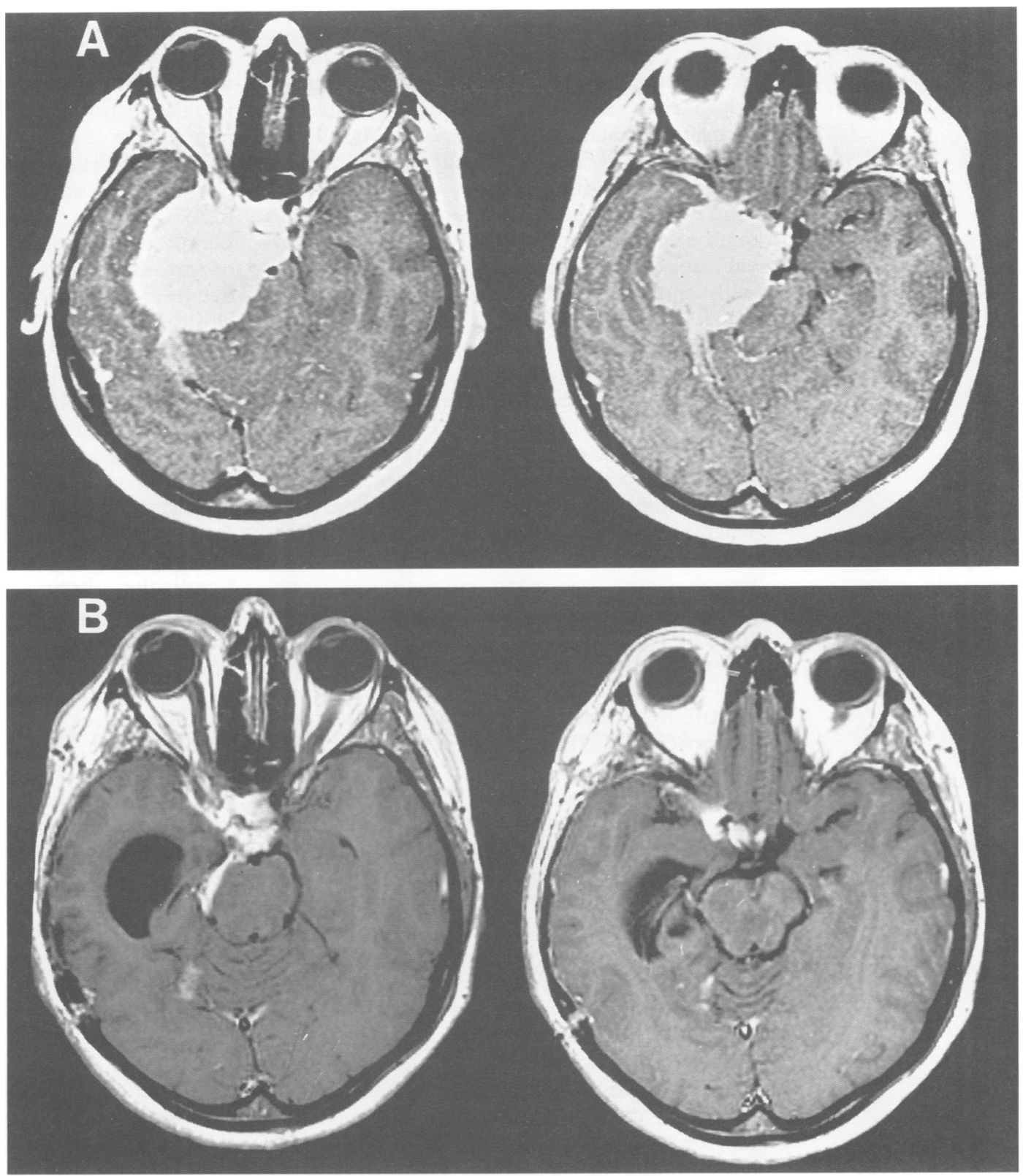

the overall permanent surgical morbidity of $28 \%$. Of those, however, three were minor neurological impairments. The remaining two patients with moderate to severe deficits were responsible for an $11 \%$ incidence of major surgical morbidity. One has a pronounced hemiparesis which prevents her from returning to her preoperative activity, while being independent at home. The other has lost a preoperative useful hearing and facial nerve function (table).

\section{Discussion}

The extremely high hazard of operative death associated with the removal of petroclival meningiomas in the premicroscopic era of neurosurgery was successfully overcome from the mid-1980s on. All recent series show a mortality below $10 \% .{ }^{1-19}$ This success was based on anatomical studies and reports reflecting the dedication of specialised groups in the development and refinement of neurosurgical techniques. ${ }^{272444}$ These publications, however, often focused on technique rather than discussing details of outcome. The authors' inventiveness earns the merit of reducing mortality and morbidity dramatically. However, we found their conclusion to advocate radical tumour removal as the surgical goal with permanent morbidities in up to $50 \%$ and severe disabilities in up to $18 \%$ of patients confusing. Very rarely has this philosophy been questioned. ${ }^{20}$

Recently two publications appeared that focused on outcome after the resection of petroclival meningiomas. ${ }^{2123}$ The authors reviewed a large number of their own cases, most of which had been published earlier in multicentre studies and reached conclusions that "have modified the authors' present approach to these lesions". Our group was always rather unsure in thinking of radical surgical removal as the primary surgical goal in every case, although we were tempted to. In fact, until not long ago we thought that our attitude might be too conservative. Reviewing our series, however, showed us that this was not the case, as discussed in the next sections. 


\section{Surgical approaches}

We have only used lateral approaches to the skull base, as we consider that anterior approaches such as transfacial, transoral, transmandibular, or extended transbasal routes 343537394144 are basically and primarily suited for extradural disease, which is in accordance with the literature. Some lateral routes such as the transcondylar ${ }^{2427}$ or infratempo$\mathrm{ral}^{7}$ approach are rarely used, by contrast with those around or through the petrous bone. ${ }^{14-68-1315-192123252831-3337}$ Despite the confusing nomenclature, they all derive from a common denominator. In simple terms, a standard suboccipital, or subtemporal trepanation, or both are combined with a varying degree of petrous bone resection. Only with complete preoperative hearing loss is a total petrosectomy (transcochlear) indicated whereas otherwise a "tailored" pyramid resection should be performed. Most often-also in our series-a combined subtemporal/suboccipital trepanation with posterior petrosectomy is performed. While providing excellent exposure, these complex routes have an inherent risk for operative complications which contribute to early postoperative dysfunction. In particular, CSF leaks and subsequent infections were seen in $28 \%$ of our patients and caused a prolonged period of recovery, a fact that is also appreciated in the literature. ${ }^{2123}$ This high rate may be lowered by meticulous dural closure and the use of rotating muscle and fascia flaps. Another problem, despite advanced anaesthesiological management of brain relaxation, is temporal lobe retraction especially on the left side. In our series $27 \%$ of cases in which a left sided approach was used had postoperative neuropsychological impairment which again prolonged the period of recovery. This dysfunction is most likely caused by impairment of venous drainage and may be avoided or alleviated by paying particular attention to the venous anatomy and by using an appropriate surgical technique. Although these early postoperative deficits improved in all patients, similar to the experience of Sekhar et $a l,{ }^{23}$ they must be considered as a potential cause of severe sequelae and therefore discussed in the counselling of the patients.

Permanent problems that were related to the approach did occur with respect to petrous bone drilling. In two patients $(10 \%)$ there was impairment of the cranial nerves VII and VIII. This constituted a major morbidity in one of the patients. Also in the above mentioned published series inadvertent sacrifice of useful hearing or facial function that recovered only incompletely after reconstructive surgery is described in up to $16 \%$.

\section{Amount of resection and operative complications \\ The question is, whether all tumours in all patients should be radically resected or whether some patients and some tumours pre- clude complete removal because of an unac- ceptable high risk of neurological deficits. In}

theory a radical excision of these "benign" lesions will best prevent recurrence. However, the natural history (for example, growth rate) and the recurrence rates after surgery-including incompletely resected lesions-are not fully understood and vary in other series between $13 \%$ and $20 \%$ after a follow up of up to $6 \cdot 1$ years. ${ }^{12161721-23}$ Whether adjuvant radiation therapy is helpful in prolonging the interval or preventing progression is still matter of debate. ${ }^{45-47}$ However, these figures alone suggest that - at least for elderly patients-subtotal removal is a valid option. ${ }^{21}{ }^{2348}$ We have so far experienced neither recurrence nor regrowth in our patients after an, admittedly short, follow up of 18 months on average.

On analysing our operative mortality and morbidity two facts are apparent: (1) Our sole operative death and one of our two major permanent disabilities, a hemiparesis, resulted from attempted radical tumour dissection from the brain stem, when a clear tumour/brain stem interface was not visible. Sekhar et $a l^{23}$ and Couldwell et $a l^{21}$ both describe the phenomenon that some of these lesions show poor planes of dissection, with pial invasion of the brain stem parasitising its microvascular supply. They both conclude that this situation prohibits complete removal and may be predicted by the presence of brain stem oedema on preoperative MRI. (2) The incidence of only two (11\%) permanent cranial neuropathies related to the cavernous sinus-both minor abducens nerve paresiscompares favourably with the other series mentioned. The reason is most probably that we did not usually attempt to completely remove tumour parts in the cavernous sinus. The figure illustrates a typical example (patient 18) for this policy, which we adapted over time. In fact, tumour extension into the cavernous sinus by itself should not generally prevent the pursuance of complete tumour removal. Particularly, tumours in the posterior cavernous sinus may be separable from cranial nerves, with good long term function. However, earlier efforts at radical removal in every case by some of the authors, ${ }^{40}$ who proposed reconstruction of oculomotor nerves, have been rather disappointing and now a more conservative attitude with respect to cavernous sinus surgery is advocated by those authors. $^{2123}$ The high incidence of vascular accidents with radical cavernous sinus resection that occurs despite preoperative balloon occlusion testing etc ${ }^{49}$ further stresses the need for a more cautious approach. In a very recent publication Larson et $a l^{50}$ describe the previously unreported phenomenon that "benign" meningiomas sometimes infiltrate cranial nerves in the cavernous sinus. They conclude that "the hope of total removal of a meningioma may be futile and, in the long term, may provide no advantage over treatment options with lower morbidity".

Our overall ratio of complete resections $(68 \%)$, surgical mortality $(5 \%)$, and permanent minor $(17 \%)$ or major (11\%) deficits can also be favourably compared with other published series. ${ }^{2123}$ As in all other series mortality 
and morbidity increases with increasing tumour size, and especially early postoperative dysfunction is naturally correlated to older age.

\section{Conclusions}

From our own experiences and failures and the recent literature, we conclude that radical resection of petroclival meningiomas is limited or even precluded by cavernous sinus involvement and brain stem adhesion, as both situations considerably increase the risk of permanent morbidity and mortality. Because morbidity and mortality are also correlated with tumour size, surgery should not be delayed in younger patients. Older patients and those with concomittant severe general disease should only be operated on when symptomatic, as the prolonged phase of recovery increases the risk of secondary fatal complications.

1 Al Mefty O, Fox JI, Smith RR. Petrosal approach for petroclival meningiomas. Neurosurgery 1988;22:510-7.

2 Babu RP, Sekhar LN, Wright DC. Extreme lateral transcondylar approach: technical improvements and lessons learned. $\mathcal{F}$ Neurosurg 1994;81:49-59.

3 Baldwin HZ, Spetzler RF, Wascher TM, Daspit CP. The far lateral combined supra- and infratentorial approach: clinical experience. Acta Neurochir (Wien) 1995;134: 155-8.

4 Bricolo AP, Turazzi S, Talacchi A, Cristofori L. Microsurgical removal of petroclival meningiomas: a report of 33 patients. Neurosurgery 1992;31:813-25.

5 Canalis RF, Black K, Martin N, Becker D. Extended retrolabyrinthine transtentorial approach to petroclival lesions. Laryngoscope 1991;101:6-13.

6 Cantore G, Delfini R, Ciapetta P. Surgical treatment of petroclival meningiomas: experience with 16 cases. Surg Neurol 1994;42:105-11.

7 Goel A. Extended middle fossa approach for petroclival lesions. Acta Neurochir (Wien) 1995;135:78-83.

8 Hakuba A, Nishimura S, Jang BJ. A combined retroauricular and preauricular transpetrosal transtentorial approach to clivus meningiomas. Surg Neurol 1988;30:108-16.

9 Kawase T, Shiobara R, Toya S. Anterior transpetrosaltranstentorial approach for spheno-petroclival meningiomas: surgical method and results in 10 patients. Neurosurgery 1991;28:869-75.

10 Kawase T, Shiobara R, Toya S. Middle fossa transpetrosaltranstentorial approaches for petroclival meningiomas. Selective pyramid resection and radicality. Acta Neurochir (Wien) 1994;129:113-20.

11 King WA, Black KL, Martin NA, et al. The petrosal approach with hearing preservation. $f$ Neurosurg 1993; 79:508-14.

12 Mayberg MR, Symon L. Meningiomas of the clivus and apical petrous bone: report of 35 cases. $\mathcal{f}$ Neurosurg 1984;65:160-7.

13 Pensak ML, van Loveren HR, Tew JM, Keith RW. Transpetrosal access to meningiomas juxtaposing the temporal bone. Laryngoscope 1994;104:814-20.

14 Pomeranz S, Umansky F, Elidan J, et al. Giant cranial base tumors. Acta Neurochir (Wien) 1994;129:121-6.

15 Samii M, Ammirati M, Mahran A, et al. Surgery of petroclival meningiomas: report of 24 cases. Neurosurgery 1989; 24:12-7

16 Samii M, Tatagiba $M$. Experience with 36 surgical cases of petroclival meningiomas. Acta Neurochir (Wien) 1992; 118:27-32.

17 Sekhar LN, Javed T, Janetta PJ. Petroclival meningiomas. In: Sekhar LN, Janecka IP, eds. Surgery of cranial base In: Sekhar LN, Janecka IP, eds. Surgery of cran

18 Spetzler RF, Daspit CP, Pappas CT. The combined supraand infratentorial approach for lesions of the petrous and clival regions: experience with 46 cases. $\mathcal{f}$ Neurosurg 1992;76:588-99.

19 Thedinger BA, Glasscock ME, Cueva RA. Transcochlear transtentorial approach for removal of large cerebellopontine angle meningiomas. Am f Otol 1992;13:408-15.

20 Ojemann RG. Skull base surgery: a perspective. $\mathcal{F}$ Neurosurg 1992;76:569-70.

21 Couldwell WT, Fukushima T, Giannotta SL, Weiss MH.
Petroclival meningiomas: surgical experience in 109 cases. 7 Neurosurg 1996;84:20-8.

22 Holmes B, Sekhar L, Sofaer S, et al. Outcome analysis in cranial base surgery-preliminary results. Acta Neurochir (Wien) 1995;134:136-8.

23 Sekhar LN, Swamy NKS, Jaiswal V, et al. Surgical excision of meningiomas involving the clivus: preoperative and intraoperative features as predictors of postoperative functional deterioration. $\mathcal{F}$ Neurosurg 1994;81:860-8.

24 Al Mefty O, Borba LAB, Aoki N, et al. The transcondylar approach to extradural nonneoplastic lesions of the craniovertebral junction. F Neurosurg 1996;84:1-6.

25 Ammirati M, Ma J, Cheatham ML, et al. Drilling the posterior wall of the petrous pyramid: a microneurosurgical anatomical study. $₹$ Neurosurg $1993 ; 78: 452-5$.

26 Baldwin HZ, Miller CG, van Loveren HR, et al. The far lateral/combined supra- and infratentorial approach. A human cadaveric prosection model for routes of access to the petroclival region and ventral brain stem. $\mathcal{F}$ Neurosurg the petroclival

27 Bertalanffy $H$, Seeger $W$. The dorsolateral, suboccipital, transcondylar approach to the lower clivus and anterior portion of the craniocervical junction. Neurosurgery 1991; 29:815-21.

28 Couldwell WT, Fukushima T. Cosmetic mastoidectomy for the combined supra/infratentorial transtemporal approach: technical note. $\mathcal{F}$ Neurosurg 1993;79:460-1.

29 Day JD, Fukushima T, Giannotta SL. Microanatomica study of the extradural middle fossa approach to the petroclival and posterior cavernous sinus region: description of the rhomboid construct. Neurosurgery 1994;34: 1009-16.

30 Jackler RK, Sim DW, Gutin PH, Pitts LH. Systematic approach to intradural tumors ventral to the brainstem. Am $\mathcal{F}$ Otol 1995;16:39-51.

31 Miller CG, van Loveren HR, Keller JT, et al. Transpetrosal approach: surgical anatomy and technique. Neurosurgery 1993;33:461-9.

32 Sasaki T, Taniguchi $M$, Suzuki I, Kirino T. En bloc petrosectomy using a Gigli saw for petroclival lesions Technical note. f Neurosurg 1995;83:559-60.

33 Tedeschi $\mathrm{H}$, Rhoton AL. Lateral approaches to the petroclival region. Surg Neurol 1994;41:180-216.

34 Ammirati M, Ma J, Cheatham ML, et al. The mandibular swing transcervical approach to the skull base: anatomical study. F Neurosurg 1993;78:673-81.

35 Beals SP, Joganic EF. Transfacial exposure of anterior cranial fossa and clival tumors. BNI Quarterly 1992;8:2-18.

36 De Oliveira E, Tedeschi M, Siqueira MG, Peace DA. The pretemporal approach to the interpeduncular and petro-
clival region. Acta Neurochir (Wien) 1995;136:204-11.

37 Lalwani AK, Kaplan MJ, Gutin PH. The transsphenoethmoid approach to the sphenoid sinus and clivus. Neurosurgery 1992:31:1008-14.

38 Neil-Dwyer G, Evans BT, Lang DA, et al. Craniofacial osteotomies for skullbase access. Acta Neurochir (Wien) 1995;134:5-15.

39 Sandor GBK, Charles DA, Lawson VG, Tator CH. Transoral approach to the nasopharynx and clivus using the LeFort I osteotomy with midpalatal split. Int $\mathcal{F}$ Oral Maxillofac Surg 1990;14:352-5.

40 Sekhar LN, Burgess J, Akin O. Anatomical study of the cavernous sinus emphasizing operative approaches and related vascular and neural reconstruction. Neurosurgery 1987;21:806-16.

41 Sekhar LN, Nanda A, Sen CN, et al. The extended frontal approach to tumors of the anterior, middle and posterior approach to tumors of the anterior, midd
skull base. $\mathcal{F}$ Neurosurg 1992;76:198-206.

42 Sekhar LN, Lanzino G, Sen CN, Pomeranz S. Reconstruction of the third through sixth cranial nerves Reconstruction of the third through sixth cranial nerves
during cavernous sinus surgery. $F$ Neurosurg 1992;76: during $935-43$.

43 Umansky F, Elidan J, Valarezo A. Dorello's canal: a microanatomical study. F Neurosurg 1991;75:294-8.

44 Uttley D, Moore A, Archer DJ. Surgical management of midline skull-base tumors: a new approach. $\mathcal{f}$ Neurosurg 1989;71:705-16.

45 Goldsmith BJ, Wara WM, Wilson CB, Larson DA Postoperative irradiation for subtotally resected meningiomas. A retrospective analysis of 140 patients treated from 1967 to 1990 . $\mathcal{F}$ Neurosurg 1994;80:195-201.

46 Lundsford DL. Contemporary management of meningiomas: radiation therapy as an adjuvant and radiosurgery as an alternative to surgical removal? $\mathcal{f}$ Neurosurg 1994;80:187-90.

47 Newman SA. Meningiomas: a quest for the optimum therapy. $\mathcal{F}$ Neurosurg 1994;80:191-4.

48 Nishizaki $T$, Kamiryo $T$, Fujisawa $H$, et al. Prognostic implications of meningiomas in the elderly (over 70 years old) in the era of magnetic resonance imaging. Acta Neurochir (Wien) 1994;126:59-62.

49 Origitano TC, Al-Mefty O, Leonetti JP, et al. Vascular consideration and complications in cranial base surgery. Neurosurgery 1994;35:351-63.

50 Larson JL, van Loveren HR, Balko G, Tew JM. Evidence of meningioma infiltration into cranial nerves: clinical implication for cavernous sinus meningiomas. $f$ Neurosurg 1995;83:596-9. 